\title{
Change of Sensation Related to Implant Placement: Case Report
}

\begin{abstract}
Placement of dental implants has become a routine practice in many dental offices. The surgical procedure, however, carries an uncommon but serious risk of neurosensory injury when performed in the posterior region of the mandible. Dental implant surgery performed above the course of the inferior alveolar canal and mental foramen is probable to nerve injury complication. Nerve injury can occur in the form of paresthesia, dysesthesia, analgesia, or anesthesia. Sensory damage affects pronunciation and food intake, adversely affects the patient's quality of life, and influences his or her social life and psychological condition. This case report describes changes in sensation related to implant placement.
\end{abstract}

\section{Introduction}

Implant therapy has been well documented to have high success rate to restore partially and fully edentulous patients $[1,2]$. With increased patient acceptance for implant treatment, the placement of dental implants has become a routine practice in many dental offices. The surgical procedure, however, carries an uncommon but serious risk of neurosensory injury when performed in the posterior region of the mandible.

The inferior alveolar nerve enters the mandibular canal at the mandibular foramen and travels laterally from the medial aspect in the third molar region, exiting at the mental foramen. Within the canal, the nerve is approximately $3 \mathrm{~mm}$ in diameter [3]. Dental implant surgery performed above the course of the inferior alveolar canal and mental foramen is probable to nerve injury complication. Nerve injury associated with implant placement may occur during each step of the procedure, from injections of local anesthetic, osteotomy preparation, to implant placement. One of the most common complications associated with nerve injury during implant surgery is altered sensation [4].

Nerve injury can occur in the form of paresthesia, dysesthesia, analgesia, or anesthesia. The clinical presentation is a temporarily or permanently altered sensation in the ipsilateral mental region, including the lower lip and chin. Sensory damage affects pronunciation and food intake, adversely affects the patient's quality of life, and influences his or her social life and psychological condition $[5,6]$. The incidence rate of transient hypoesthesia and anesthesia caused by implant surgery has been reported to be $0 \%$ to $43.5 \%$ [7] and the incidence rate of permanent sensory damage ranged from $0 \%$ to $13 \%$ [4]. Literature also suggested that paresthesia, if it lasted for a long time, often led to permanent deficit [8].

This case report describes changes in sensation related to implant placement.

\section{Case Report}

A 52-year-old, Caucasian female with non-contributory medical

\section{Journal of Oral Biology}

\section{Chih-Chieh Liang, Wendy CW Wang*, Thomas Pellech, Takanori Suzuki, Sang-Choon Cho and Peter Loomer}

Ashman Department of Periodontology and Implant Dentistry, New York University College of Dentistry, New York, USA

\section{*Address for Correspondence}

Wendy CW Wang, Ashman Department of Periodontology and Implant Dentistry, New York University College of Dentistry, New York, USA, E-mail: wcw251@nyu.edu

\section{Submission: 29 March 2016}

Accepted: 04 May 2016

Published: 09 May 2016

Copyright: () 2016 Liang CC, et al. This is an open access article distributed under the Creative Commons Attribution License, which permits unrestricted use, distribution, and reproduction in any medium, provided the original work is properly cited.

Reviewed \& Approved by: Dr. Rajiv Saini, Department of Periodontology \& Oral Implantology, Pravara Institute of Medical Sciences, Maharastra, India

history presented to New York University, College of Dentistry, Department of Implant Dentistry in March 2013 for an implant to replace her missing mandibular right first molar, \#30. Clinical and radiographic examination revealed adequate bone volume for implant placement (Figures 1 and 2).

Local infiltration anesthesia was administered. A mid-crestal incision and intra-sulcular incisions between teeth \#29 and \#31 were made. Following buccal full thickness flap elevation and osteotomy preparation, a Nobel Replace Select TIU Tapered 5.0 x $10 \mathrm{~mm}$ implant was inserted with the aid of a surgical guide (Figures 3-5). The patient did not demonstrate any "electric-shock-type" sensation

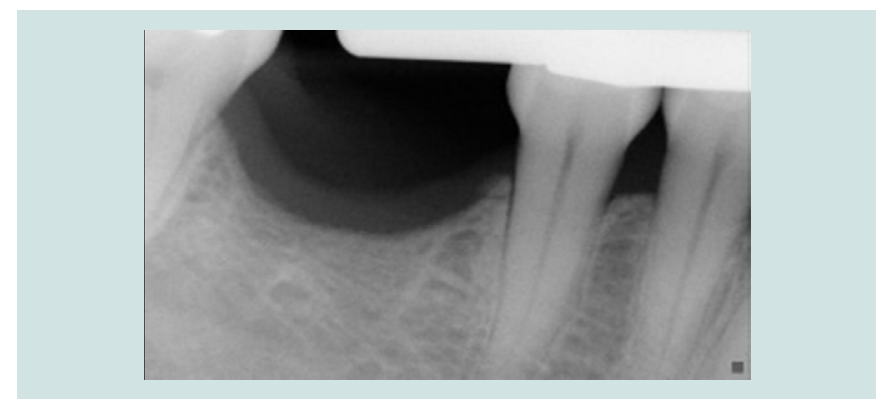

Figure 1: Pre-operative radiograph of edentulous site \#30.

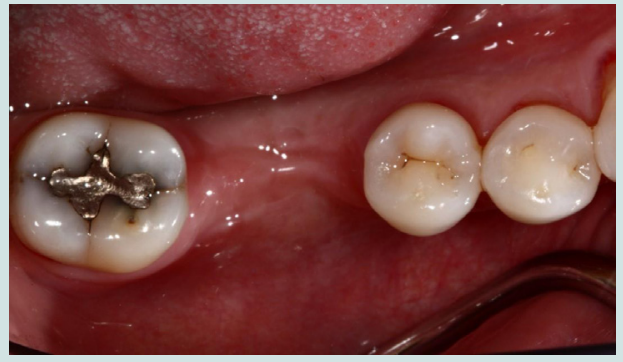

Figure 2: Pre-operative intra-oral view of edentulous site \#30. 
Citation: Liang CC, Wang WCW, Pellech T, Suzuki T, Cho SC, et al. Change of Sensation Related to Implant Placement: Case Report. J Oral Bio. 2016; $3(1): 4$.

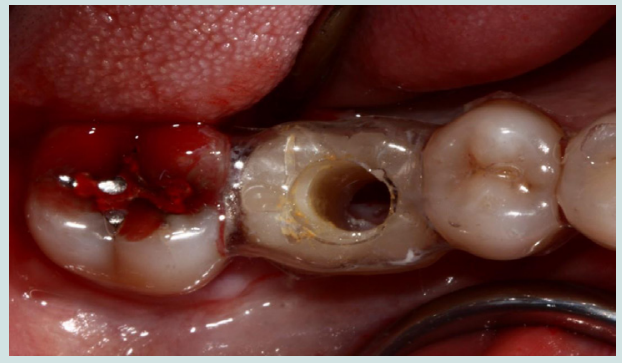

Figure 3: Implant placement following the surgical guide.

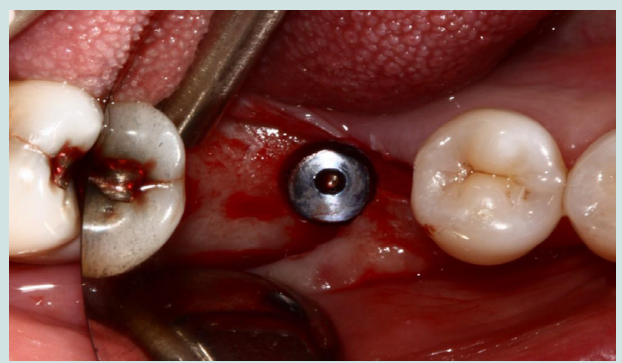

Figure 4: Insertion of Nobel Replace Select $5.0 \times 10 \mathrm{~mm}$ implant.

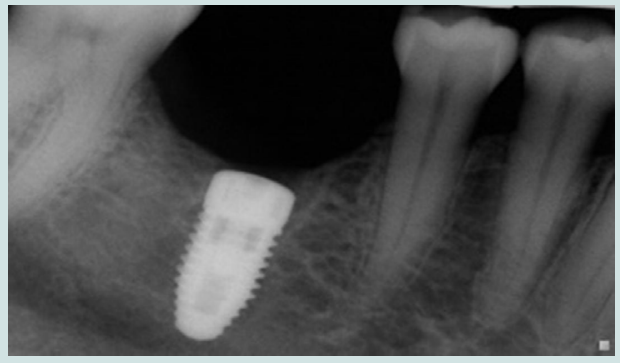

Figure 5: Post-operative radiograph of implant placement.

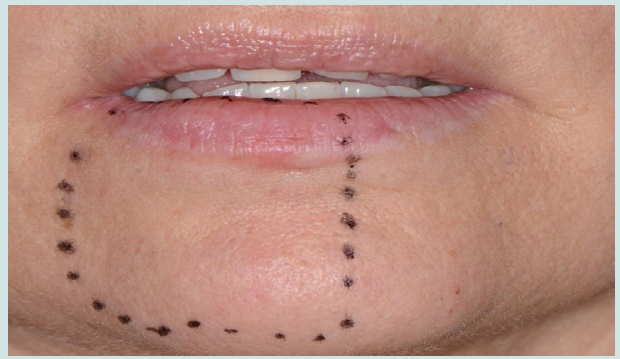

Figure 6: Clinical plotting of paresthesia area using two-point test technique.

during the administration of local anesthetic or any intra-operative procedures. The flap was replaced with Vicryl 4-0 interrupted sutures. The patient was given prescriptions for $500 \mathrm{mg}$ amoxicillin (t.i.d. for 7 days), Tylenol with codeine No. 3 (p.r.n.), and chlorhexidine $0.12 \%$ (0.5 oz twice daily for 14 days).

The patient reported persistent numbness after the effect of local anesthetic has worn off. Two-point discrimination test was performed with a marker pen and the area of the numbness was mapped (Figure
6). The test was repeated a week after and slight improvement was reported. The patient was advised to take Vitamin B-12 $1500 \mathrm{mcg}$ daily.

At three-week follow-up appointment, mapping of the area of altered sensation was performed and improvement of sensation was noted. The patient described tingling sensation in place of complete numbness (Figure 7). No further change in sensation was reported one week after despite the continuous intake of Vitamin B-12 supplements.

The patient declined explantation and elected to monitor, however, no further improvement was reported after three months of observation and the patient received cone beam computerized tomography (CBCT) of the mandibular arch for assessment (Figure 8a). The proximity of the implant at \#30 site to the inferior alveolar nerve necessitated the removal of the implant.

The implant was removed in June 2013. Following administration

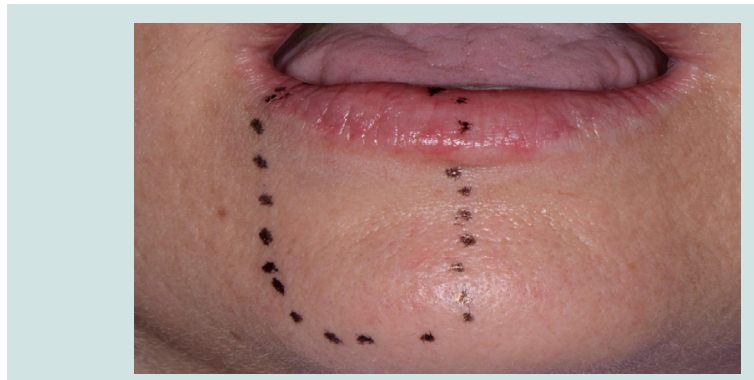

Figure 7: Clinical plotting of paresthesia at three-week follow up showing a reduced area of altered sensation.

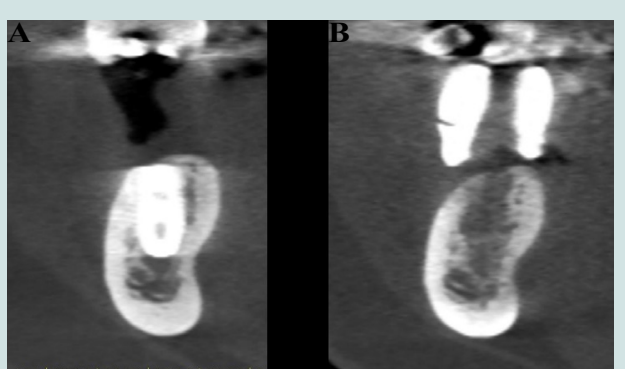

Figure 8: (a) Computerized tomography showing close proximity of the implant to the inferior alveolar nerve (left)

(b) Computerized tomography demonstrating signs of socket healing after the implant removal (Right)

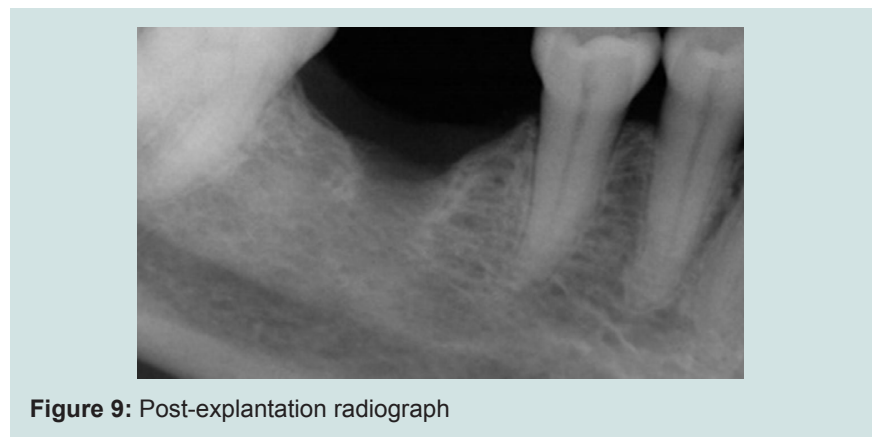


Citation: Liang CC, Wang WCW, Pellech T, Suzuki T, Cho SC, et al. Change of Sensation Related to Implant Placement: Case Report. J Oral Bio. 2016; $3(1): 4$.

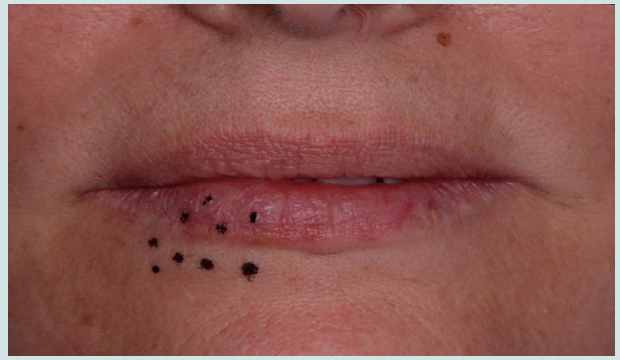

Figure 10: Clinical plotting of paresthesia area 13 months post explantation.
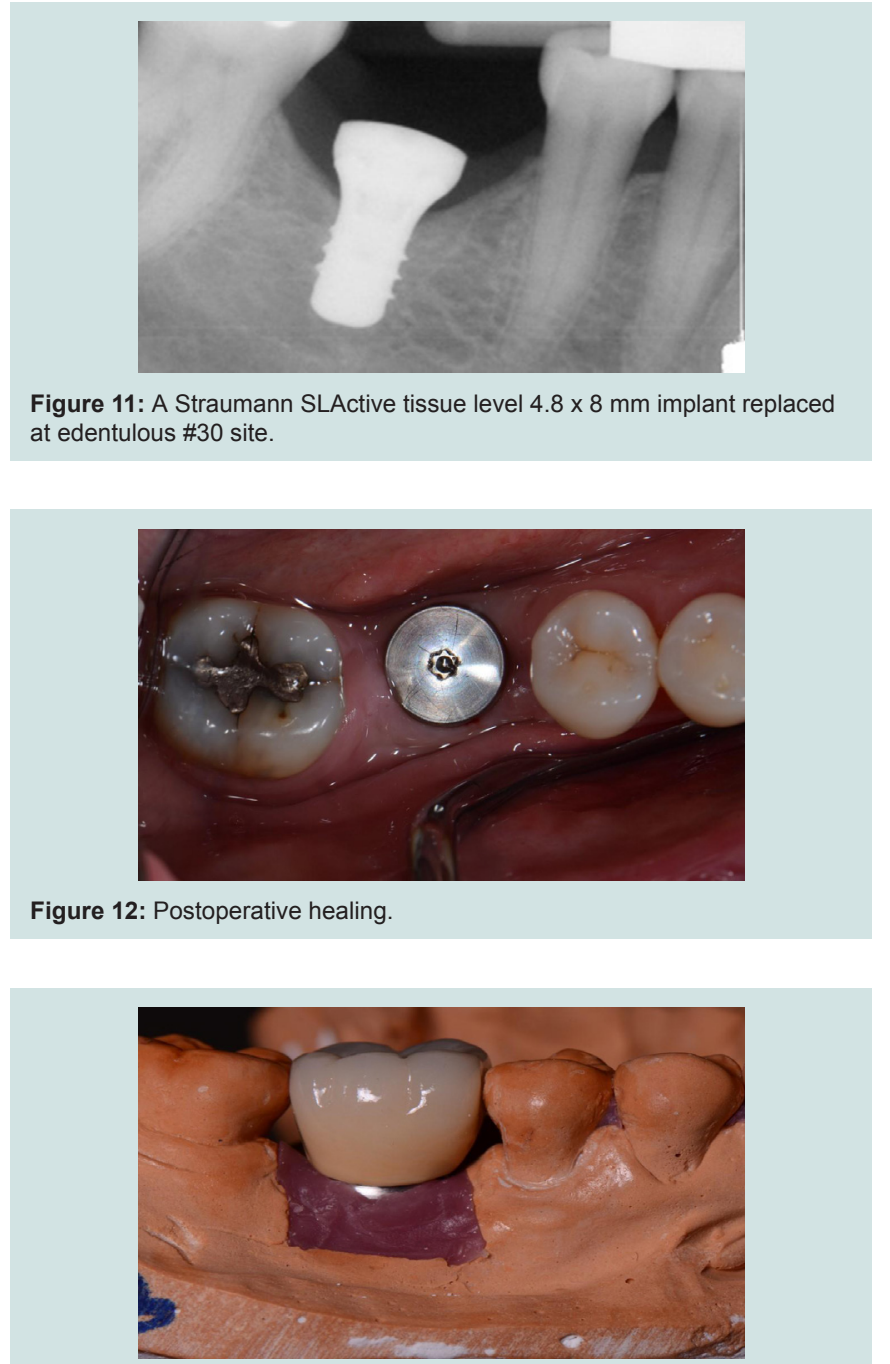

Figure 13: Cement-retained implant restoration No.30 on cast.

of local anesthetic, a mid-crestal with intra-sulcular incisions between teeth \#29 and \#31 was made. Initially, a trephine bur was used to reduce the retention of the implant, which was then gently luxated and removed with forceps to avoid further damage to the nerve. The flap was then closed with Chromic Gut 4-0 interrupted sutures. The patient was given prescriptions for $500 \mathrm{mg}$ amoxicillin (t.i.d. for 7 days), Tylenol with codeine No. 3 (p.r.n.), and chlorhexidine $0.12 \%$ ( $0.5 \mathrm{oz}$ twice daily for 14 days). The patient reported marked improvement upon explanation however she remained unresponsive to cold air or water around right mandibular teeth at one-week follow-up.

The patient was examined again four months post explantation and another CBCT was taken. A significant diminishing of the parethesia had occurred, described by the patient as a $40 \%$ improvement. The patient felt tingling on both sides of her face, and could not differentiate clearly the area of the numbness. In addition, a consistent sign of socket healing was noted on CBCT (Figures 8b and 9).

The patient reported steady but slower return of sensation at six months assessment following the removal of the implant. Clinical evaluation and mapping were performed on her right side, both intraorally and extraorally. The awareness of sensation was higher on the angle of the mouth and progressively decreased as the midline was approached. The inner side of the lip had better sensation than the cutaneous side. An explorer was used to test sensation on the patient's chin, lip and the edentulous \#30 site. The patient responded positively to all areas explored. The patient also reported positively to
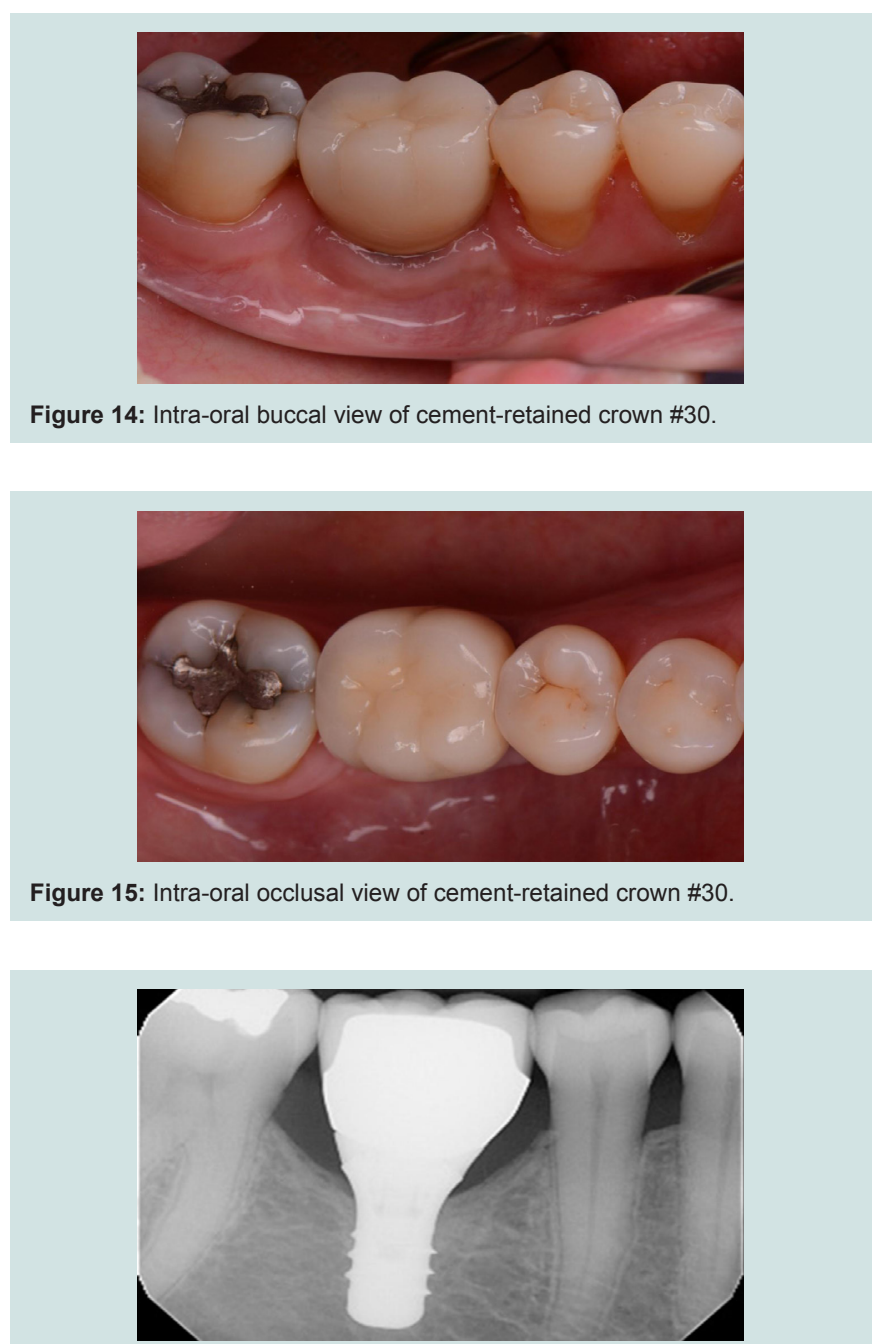

Figure 16: Post operative radiograph confirming complete seating of restoration. 
cold stimulus and tingling sensation on the right side of chin and lip.

Ten months after the removal of the implant, two-point test was performed before placing of a new implant. The mapping area has reduced to only the anterior region of the lower right lip (Figure 10). An 8-mm sandblasted and acid-etched tissue level implant (ITI, Straumann, Waldenburg Switzerland) was placed (Figure 11). Postoperative healing was unremarkable with no change in sensation relative to preoperative condition (Figure 12).

Restoration of the implant was completed seven-month post implant insertion (Figures 13-16). The patient reported complete return of sensation three month following the restoration delivery stating positively that her dentine sensitivity to cold stimulus had returned.

\section{Discussion}

The degree of sensory deficits and its subsequent level of recovery are determined by the nature of the nerve injury [9]. Classification of nerve injury was described by Seddon in 1943 and by Sunderland in $1951[10,11]$. Nerve injury resulted from minor compression of a nerve is the least consequential, contributing to only temporary interruption of conduction without loss of axonal continuity. This effect is described as "neurapraxia" [10] or "first degree injury" [11]. More severe compression or "crush" injuries cause degeneration of axons distal to the site of injury, and recovery of sensation requires regeneration of the damaged axons [11]. This injury has been referred as "axonotmesis" [10] or "second degree injury" [11].

Injuries of higher degrees may occur when a nerve is stretched. Stretching can contribute to rupture of the endoneurium and perineurium, described as "third and fourth" degree injuries. These types of injuries can lead to extensive fibrosis within the nerve trunk and the loss of axon guidance from the endoneurial tubes [11]. Extensive damage can occur with as little as $6 \%$ of rapid stretching [12]. Elevation of a mucoperiosteal flap adjacent to the mental nerve is an example that can lead to the stretching of the nerve [8].

Total severance or disruption of the entire nerve fiber is described as "neurotmesis" [10] or "fifth degree injury" [11]. Nerve transection is usually followed by a reduction in the number of axons distal to the site of the injury, and a higher reduction in diameter and conduction velocity [13].

The nerve injury described in the case report falls between the second and third degree injuries, as classified by Sunderland in which the endoneurium was interrupted, but the epineurium and perineurium remained intact. As the intrafascicular tissue components are damaged, some degree of intrafascicular fibrosis blocks the path of regenerating axons [12]. This results in fair-to-poor sensory recovery with paresthesia and increased 2-point discrimination [10]. The patient in this case report had persistent paresthesia until the implant was removed and she slowly regained complete sensory. The clinical observations placed her under the compressed injury category and are in agreement with findings published by Robinson in 1988 [9]. In his study, 13 patients who had compression types of injuries had their light touch sensation returned within 4 months of the injury, however, 6 of the 13 patients had a subjective difference in sensation in the lip and chin on the injured side, when compared with the control side. The authors suggested abnormalities in sensation which persisted for longer than 4 months could result in a long-term and possibly permanent deficit [9].

Several drugs for promoting recovery from nerve injuries have been evaluated, including vitamins $B_{1}, B_{6}$ and $B_{12}$ (the composition of the vitamin $B$ complex administered to the patient described in this case report). B complex vitamins are important for various functions of the human body, including energy functions, body defense mechanisms and red blood cell formation. Although these substances improve the regeneration of peripheral nerves in animal models, their effects in humans are not supported by scientific evidence [14].

\section{Conclusions}

This report documents sensory recovery of an area of persistent paresthesia upon the removal of the offending implant and the placement of another implant in the same vicinity did not result in recurrent paresthesia.

\section{References}

1. Adell R, Lekholm U, Rockler B, Brånemark PI (1981) A 15-year study of osseointegrated implants in the treatment of the edentulous jaw. Int $\mathrm{J}$ Oral Surg 10: 387-416.

2. Buser D, Mericske-Stern R, Bernard JP, Behneke A, Behneke N, et al. (1997) Long-term evaluation of non-submerged ITI implants. Part 1: 8-year life table analysis of a prospective multi-center study with 2359 implants. Clin Oral Implants Res 8: 161-172.

3. Snell RS (2001) Clinical neuroanatomy for medical students, (5 $5^{\text {th }}$ edn). Lippincott Williams \& Wilkins.

4. Ellies LG (1992) Altered sensation following mandibular implant surgery: a retrospective study. J Prosthet Dent 68: 664-671.

5. Abarca M, van Steenberghe D, Malevez C, De Ridder J, Jacobs R (2006) Neurosensory disturbances after immediate loading of implants in the anterior mandible: an initial questionnaire approach followed by a psychophysical assessment. Clin Oral Investig 10: 269-277.

6. Ziccardi VB, Assael LA (2001) Mechanisms of trigeminal nerve injuries. Atlas Oral Maxillofac Surg Clin North Am 9: 1-11.

7. Bartling R, Freeman K, Kraut RA (1999) The incidence of altered sensation of the mental nerve after mandibular implant placement. J Oral Maxillofac Surg 57: 1408-1412.

8. Elian N, Mitsias M, Eskow R, Jalbout ZN, Cho SC, et al. (2005) Unexpected return of sensation following 4.5 years of paresthesia: case report. Implant Dent 14: 364-367.

9. Robinson PP (1988) Observations on the recovery of sensation following inferior alveolar nerve injuries. Br J Oral Maxillofac Surg 26: 177-189.

10. Seddon HJ (1943) Three types of nerve injury. Brain 66: 237-288.

11. Sunderland $S$ (1951) A classification of peripheral nerve injuries producing loss of function. Brain 74: 491-516

12. Sunderland S (1978) Nerves and nerve injuries, $\left(2^{\text {nd }} e d n\right)$. Churchill Livingstone, Edinburgh, New York, pp. 351-361.

13. Horch KW, Lisney SJ (1981) On the number and nature of regenerating myelinated axons after lesions of cutaneous nerves in the cat. J Physiol 313 275-286.

14. Becker KW, Kienecker EW, Dick P (1990) A contribution to the scientific assessment of degenerative and regenerative processes of peripheral nerve $f$ ibers following axonotmesis under the systemic administration of vitamins B1, B6 and B12--light and electron microscopy findings of the saphenous nerve in the rabbit. Neurochirurgia (Stuttg) 33: 113-121. 